\author{
Seismic analysis of a 2-storey log house \\ Jorge M. Branco ${ }^{a}$, Paulo B. Lourenço ${ }^{b}$, Chrysl A. Aranha ${ }^{c}$ \\ ISISE, Department of Civil Engineering, University of Minho, Guimarães, Portugal \\ a jbranco@civil.uminho.pt, ${ }^{b}$ pbl@civil.uminho.pt, ${ }^{c}$ chryslaranha@gmail.com
}

Keywords: log house, timber, shaking table, seismic performance

\begin{abstract}
The current paper deals with the analysis of the results yielded by a series of tests performed to evaluate the seismic behaviour of a model log construction. The study was based on an experimental investigation performed to improve the existing knowledge on log houses subject to seismic events. The main part of the experimental work is based on a full scale shaking table test, conducted on a two-storey log house designed by the Portuguese company Rusticasa ${ }^{\circledR}$ in compliance with design rules for timber buildings. The test was performed by the University of Minho within the framework of the SERIES Project 'Multi-storey timber buildings' and was coordinated by the University of Trento, at LNEC, Lisbon, Portugal.

The geometry of the specimen, the design of the test, the setup and the instrumentation layout are first presented in this paper. The test procedure was conducted in stages with maximum accelerations (bi-directional) of $0.07 \mathrm{~g}, 0.28 \mathrm{~g}$ and $0.5 \mathrm{~g}$. The experimental results of each test have been analyzed and the resultant values of inter-storey drift, wall slippage and uplift measurements, shear deformations and hold-down forces measured are presented. Most importantly, the dynamic properties (fundamental period and mode shapes) of the system have been determined.
\end{abstract}

\title{
Introduction
}

Log houses consist of walls made by stacking horizontal logs one above the other and are one of the oldest forms of timber construction. They are built even today in regions of Scandinavia, the United States and Canada, where there are abundant forest trees and the climate is suitable for this form of construction. Most of the traditional log houses display poor seismic performance during severe earthquakes as the corner log connections are not sufficiently robust and come lose due to shear forces. In order to overcome that problem, modern log homes have improved carpentry joints and mechanical connections at the intersections between cross log walls. Although the practice of building log houses has existed since a very long time, the amount of data available on the structural properties, seismic behaviour and the load resistance mechanisms of this system is limited.

The joints between orthogonal walls, along with the friction between the carpentry joints play an important role in the stability and resistance to horizontal loads. The compression strength perpendicular to the grain and the contact area between the logs govern the resistance of the log structures to vertical load. For log shear walls, resistance to lateral loads comes from the interlock between logs, wood or steel dowels, vertical through-bolts or anchor bolts and friction between logs due to vertical loads. Current building codes only consider that the compression perpendicular to the grain and shear stress at intersections between walls are responsible for the seismic resistance. Since the exact contribution to resistance by friction and interlock between logs is not known can't be quantified with current knowledge, friction is not considered as a mechanism [1]. 


\section{Aim and Scope of the Project}

In order to obtain the European Technical Approval (ETA) for the entry of the log house under study into the commercial market, a number of experimental and numerical studies have to be performed to make a detailed characterization of the construction system. The first and second phases of the project concentrated on the investigation of the behaviour of connections between the sill logs and the foundation through a series of shear and tension tests under cyclic loading along with the characterization of the behaviour of log walls by subjecting wall specimens to monotonic and cyclic loading [2]. While the first two phases involved the study of the behaviour of individual structural components of the building system, the current phase aims at a more comprehensive study of the structure itself. It deals with the global behaviour of the structure when subjected to seismic loads, its dynamic properties, the study of the interaction of the individual components inside the real structure during an earthquake and the assessment of the failure modes.

\section{Description of the Test Building}

Geometry and layout. The house, as seen in Figure 1, is characterized by a rectangular plan of size $5.64 \mathrm{~m} \times 7.3 \mathrm{~m}$, with its total height increasing from $4.40 \mathrm{~m}$ at the edge to $5.28 \mathrm{~m}$ at the ridge, forming a gable roof. The logs used in the construction of the walls form a perfect fit with each other as they are shaped both at the top and bottom. The dimensions of the cross sections of the $\operatorname{logs}$ used are $160 \mathrm{~mm} \times 160 \mathrm{~mm}$ and $80 \mathrm{~mm} \times 160 \mathrm{~mm}$ in the outer and inner walls respectively. The logs are made from glued laminated timber of Scots Pine trees (Pinus sylvestris L.) and belong to the $\mathrm{C} 24$ class of resistance according to [3]. The plan of the structure is symmetrical in the longitudinal direction and asymmetrical in the transverse direction. In order to guarantee rigid in-plane behaviour of the diaphragm, the beams are superimposed by Oriented Strand Board (OSB) studded panels which are $22 \mathrm{~mm}$ thick. The roof structure is characterized by massive wooden rafters of cross-section $70 \mathrm{~mm} \times 190 \mathrm{~mm}$, inclined at an angle of $18^{\circ}$, over which OSB panels are nailed.

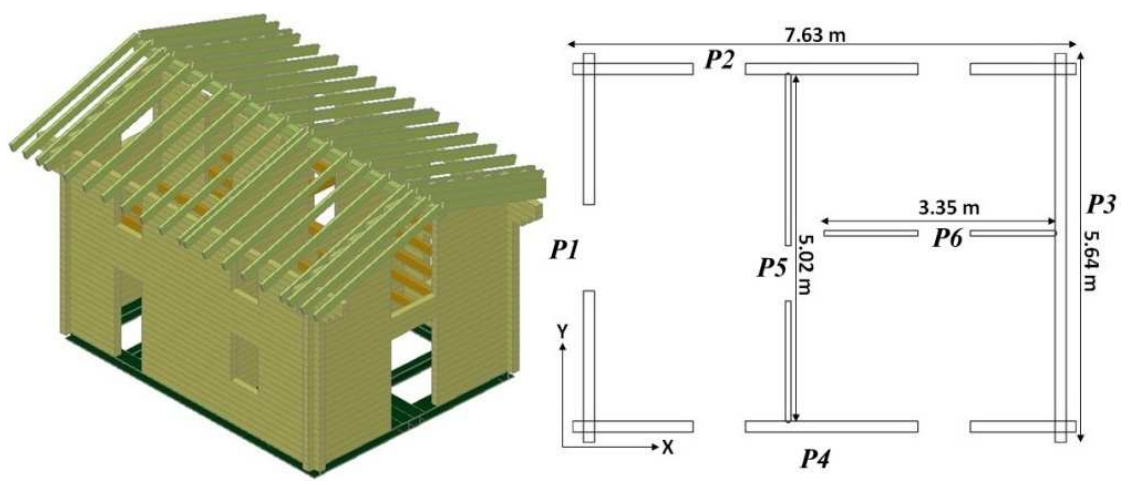

Figure 1: 3D model (left) and plan (right) of the log house

Connections. A number of mechanical fasteners in the form of screws have been provided at necessary locations in the house - around the openings, near the joints of the cross walls, between the floor beams and walls, at the ridge and at the top and bottom of the rafters. 
The connections between wooden members are in the form of halved joints when two exterior walls meet orthogonally and dovetail joints when an exterior wall meets an interior wall. The floor end joists are also appropriately grooved to form dovetail joints with the log walls. The sill logs are connected to the steel plate through M16 bolts of Class 8.8 that are spaced at intervals of $500 \mathrm{~mm}$ to ensure that the sliding between the log house and the steel lattice is minimal. These connections can be seen in Figure 2.

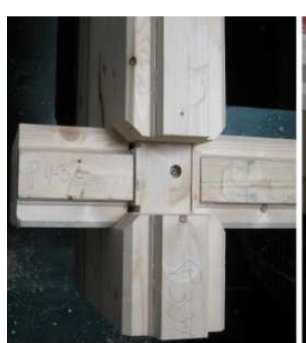

(a)

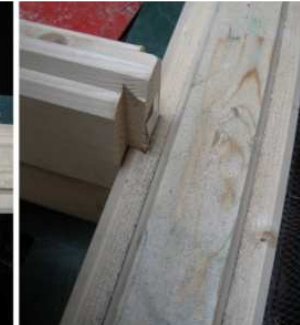

(b)

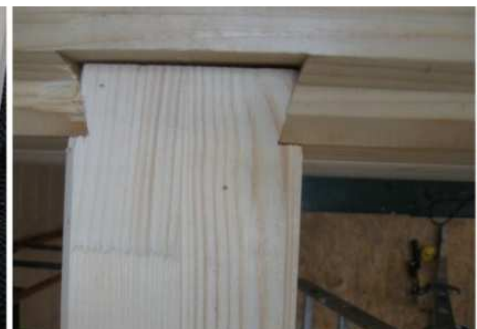

(c)

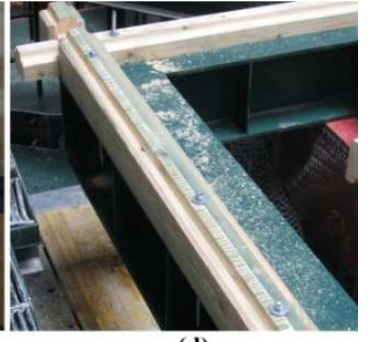

(d)

Figure 2: Connections between (a) two exterior walls (b) an exterior and an interior wall (c) floor end joist and wall (d) sill log and foundation

Seismic design considerations. As a typical log-house does not dissipate a large amount of energy, the value of $\mathrm{q}$ should be around 1.5. However, the behaviour factor is assumed to be 2 taking into account the dissipative action contributed by friction as well. Additional masses in the form of four steel platforms and 398 steel plates were placed on the inter-storey floor and the roof cover respectively in order to simulate the permanent loads and accidental loads.

\section{Design of the Test}

The design of the test is the key step in the experimental campaign because the seismic input and the parameters required for phase tuning the shaking table are determined based on the model. Prior to the seismic testing, a numerical model of the building was developed in SAP2000 [4] to obtain information on the dynamic properties and performance capability of the structure assuming the material properties obtained from previous numerical and experimental studies performed by UMinho [2].

\section{Experimental Procedure}

As the shaking table at LNEC wasn't large enough to directly accommodate the building, a lattice of steel beams was used to connect the structure to the table and provide a wider base. The steel base is composed of two identical rectangular sections which are $7 \mathrm{~m}$ long and $2.675 \mathrm{~m}$ wide that are rigidly connected together. 
All primary structural elements of the building were prefabricated in the factory Vila Nova de Cerveira and transported by truck for a distance of about $400 \mathrm{~km}$ to Lisbon. The assembly of the building was done directly over the shaking table by three workers and took four days. The stages of assembly can be seen in Figure 3.
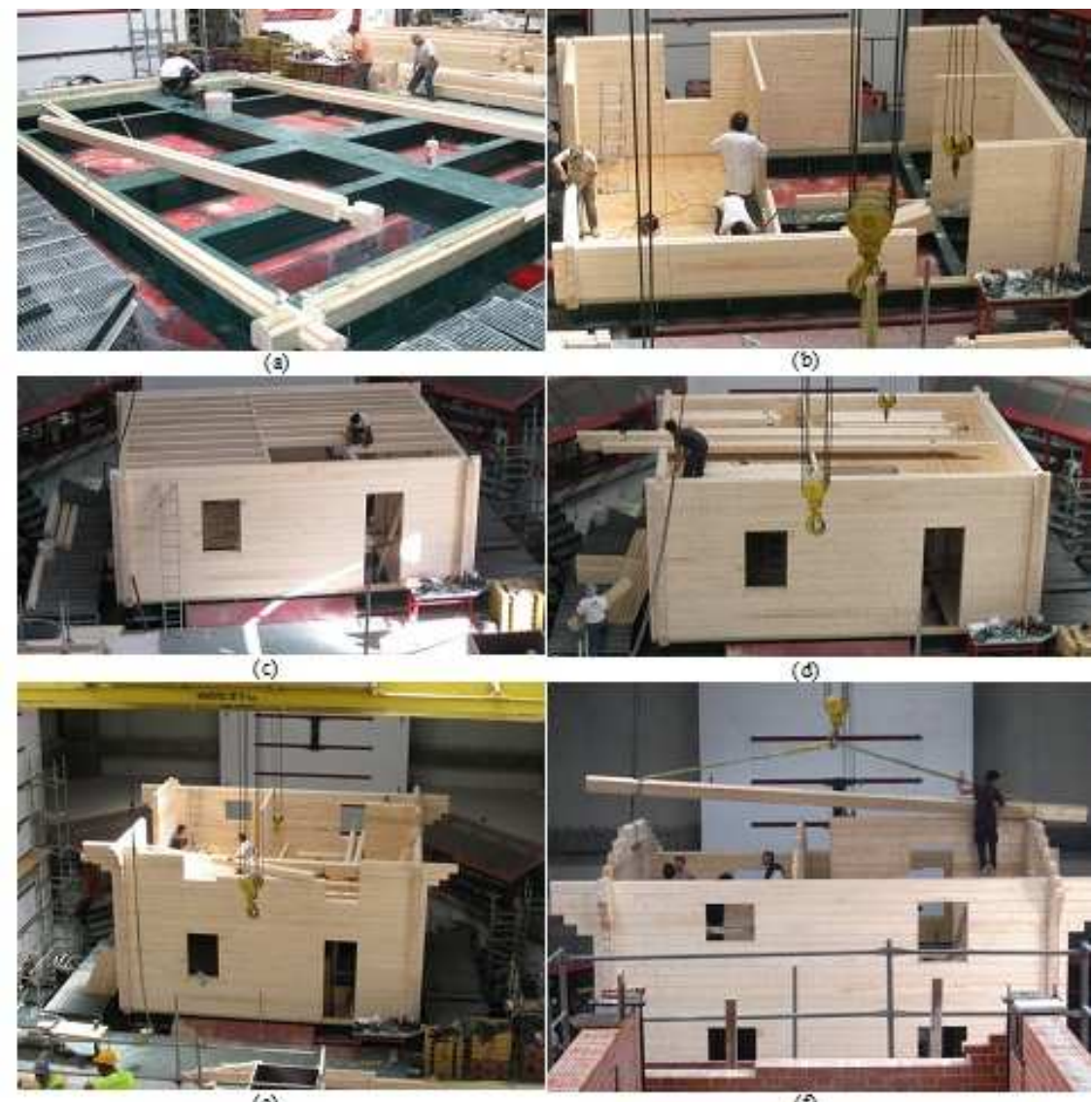

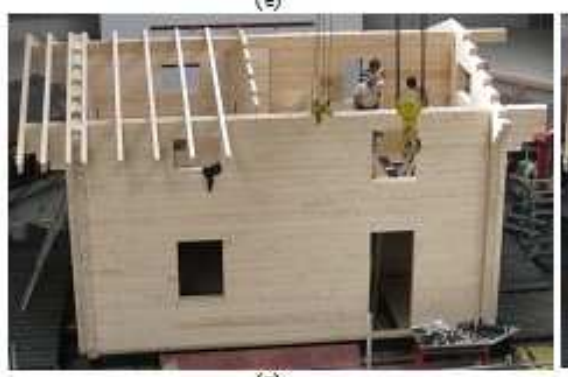

(g)

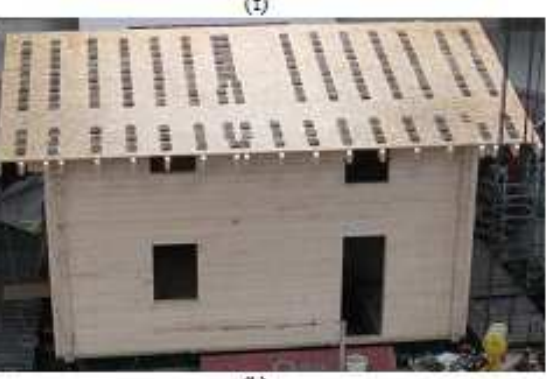

(h)

Figure 3 Stages of construction (a) connecting the bottom logs with the steel lattice (b) laying the ground floor walls (c) placing interstorey floor beams (d) nailing OSB planks to the floor joists (e) laying the first floor walls (f) positioning the ridge board (g) connecting the roof rafters (h) Completed house

Instrumentation. To monitor the accelerations, wall slippage and uplift, shear deformations, interstorey displacements and forces in the building components, a total of 80 instruments were placed at different points of interest in the building. The instruments were arranged to mainly study the behaviour of the building in the longitudinal and transverse directions and focused on observing the behaviour of five walls on the ground floor. An optical acquisition system consisting of 
infrared cameras and linear position sensors was used to continuously detect and measure absolute displacement of the control points. The data obtained during all the stages of testing right from the tuning of the shaking table to the dynamic identification of the building and the seismic tests were sampled at a sampling frequency of $125 \mathrm{~Hz}$.

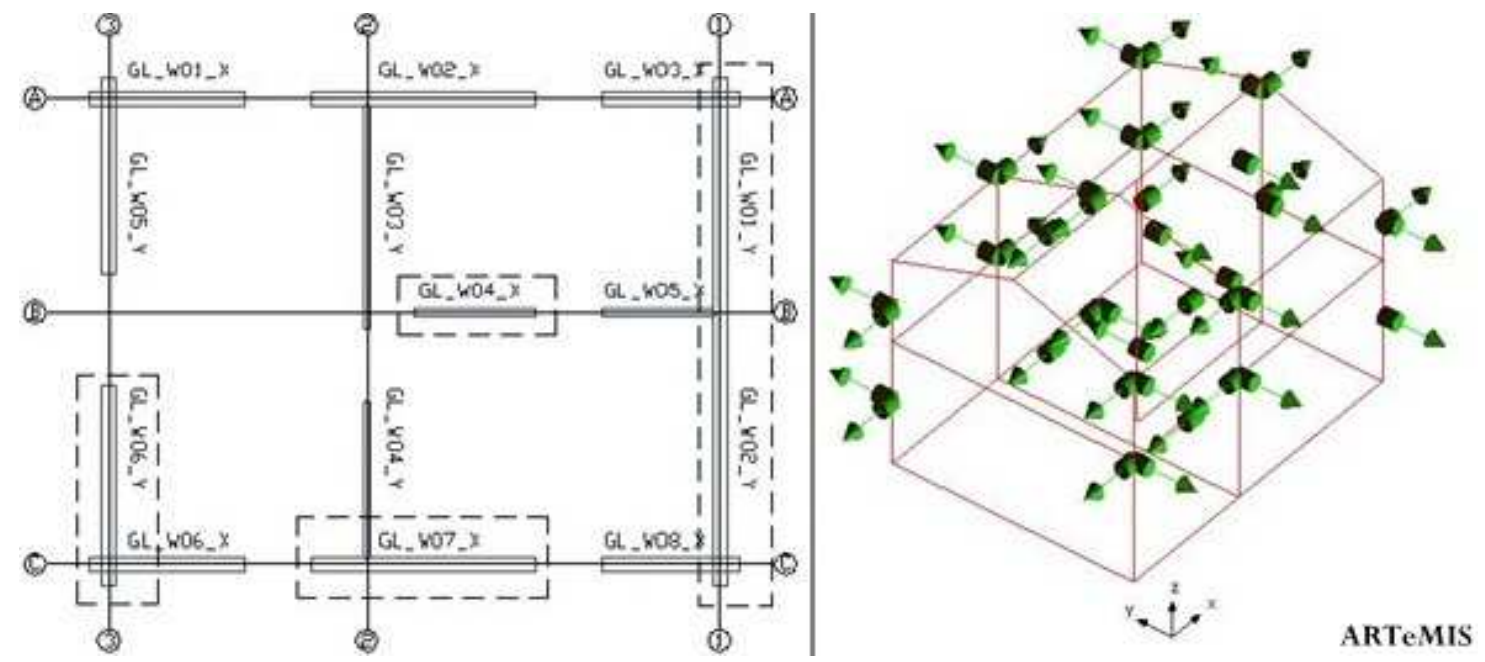

Figure 4 Monitored walls (left) and position of accelerometers in the log house (right)

Based on the pre-design of the test, the input signal chosen was the one that was registered at the Ulcinj - Hotel Albatros during the Montenegro earthquake on the $15^{\text {th }}$ of April, 1979. Figure 5 shows the acceleration time history used in the longitudinal direction.

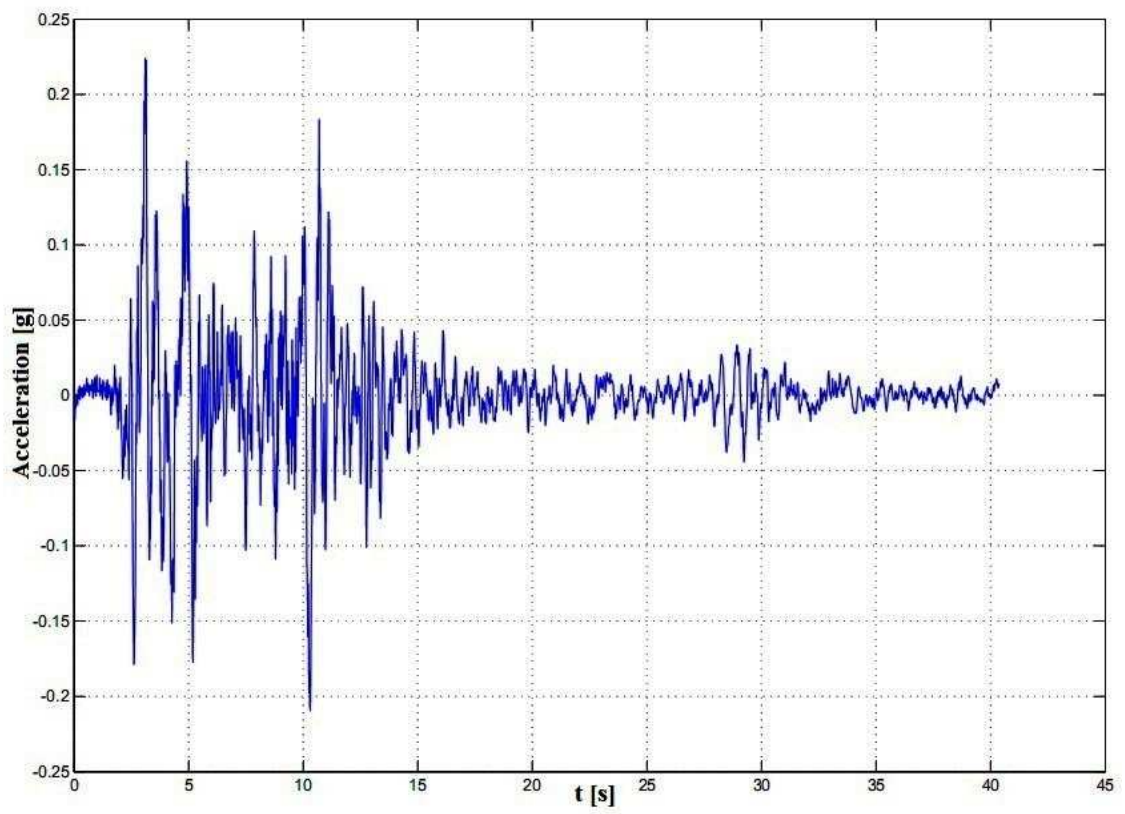

Figure 5 The accelerogram of the Montenegro earthquake recorded at the Ulcinj- Hotel Albatros station 
The acceleration time history in the $\mathrm{x}$ and $\mathrm{y}$ directions were used with peak ground accelerations of $0.181 \mathrm{~g}$ and $0.224 \mathrm{~g}$ respectively. All seismic tests were preceded and followed by a low intensity dynamic test in the form of white noise. The purpose of these tests was to calibrate the parameters necessary to control the shaking table and to conduct the dynamic identification of the structure. The test procedure followed was carried out with three different PGA values $0.07 \mathrm{~g}, 0.28 \mathrm{~g}$ and $0.5 \mathrm{~g}$. During this incremental test procedure, whenever damage occurred, an identification test was performed to assess any variation in the fundamental period of the house.

Damages observed. The building proved to have a good seismic performance and did not suffer any major damage. The first stage of the test with a maximum acceleration of $0.07 \mathrm{~g}$ produced no visible damage in the building. There were some more minor damages observed after the PGA was increased to $0.5 \mathrm{~g}$. No kind of repair intervention was carried out between the successive stages of the experiment. The following damages were observed during the test- fracture along the length of the log due to out-of-plane flexure, slippage of logs due to shear, fracture along the grain at connections between orthogonal walls due to shear, internal cracks in the log section and fracture at the top and bottom notches of the logs. The typical damages can be seen in Figure 6 .

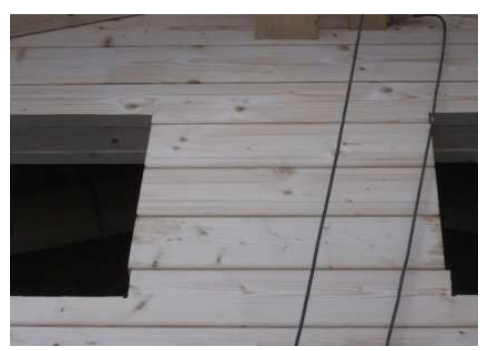

(a)

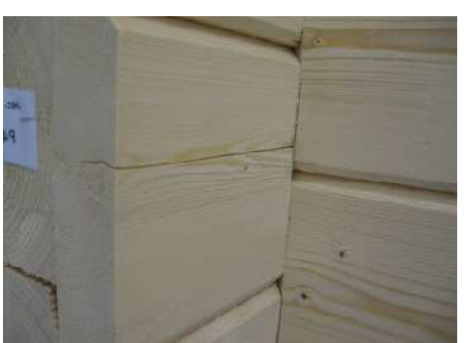

(b)

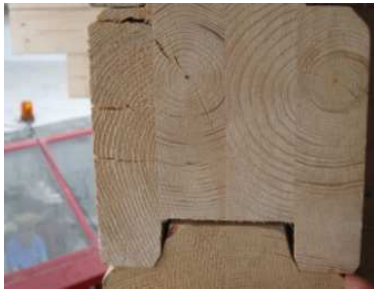

(c)

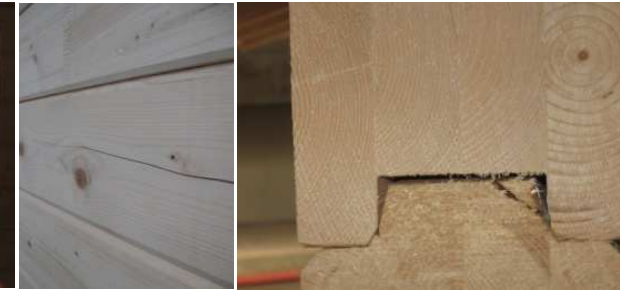

(e)

Figure 6 (a) slipping of logs in the NW part of the house (b) splitting of logs at cross wall intersections (c) cracks seen in the log cross section (d) fracture along the grain of the logs (e) damage seen at the top notch of a $\log$

\section{Analysis of Results}

From the series of dynamic characterization tests performed on the structure, information regarding the fundamental frequency, mode shapes, inter-storey drift and hold down forces was obtained.

Modal analysis. The data recorded from the accelerometer on the shaking table and the roof accelerometers was processed using input-output modal identification techniques. An antialiasing filter was used to remove the frequency content above the Nyquist frequency $(62.5 \mathrm{~Hz})$ and a Hanning window was used to overcome problems due to leakage. In the spectral analysis configuration, the overlap was set to $66.67 \%$. The fundamental frequency obtained was $5.389 \mathrm{~Hz}$ $[\mathrm{T}=0.195 \mathrm{~s}]$ during the initial characterization test (before $0.07 \mathrm{~g}$ ) and reduced to $5.109 \mathrm{~Hz}$ 
$[\mathrm{T}=0.196 \mathrm{~s}]$ during the final characterization test (after $0.05 \mathrm{~g}$ ). Only the first four modes of the structure were identified and evaluated. The first mode is a mixed mode. The second mode is longitudinal while the third mode is torsional and the fourth is transverse. Figure 7 presents the fundamental mode shape of the log house obtained using the operational modal analysis software ARTeMIS [5].

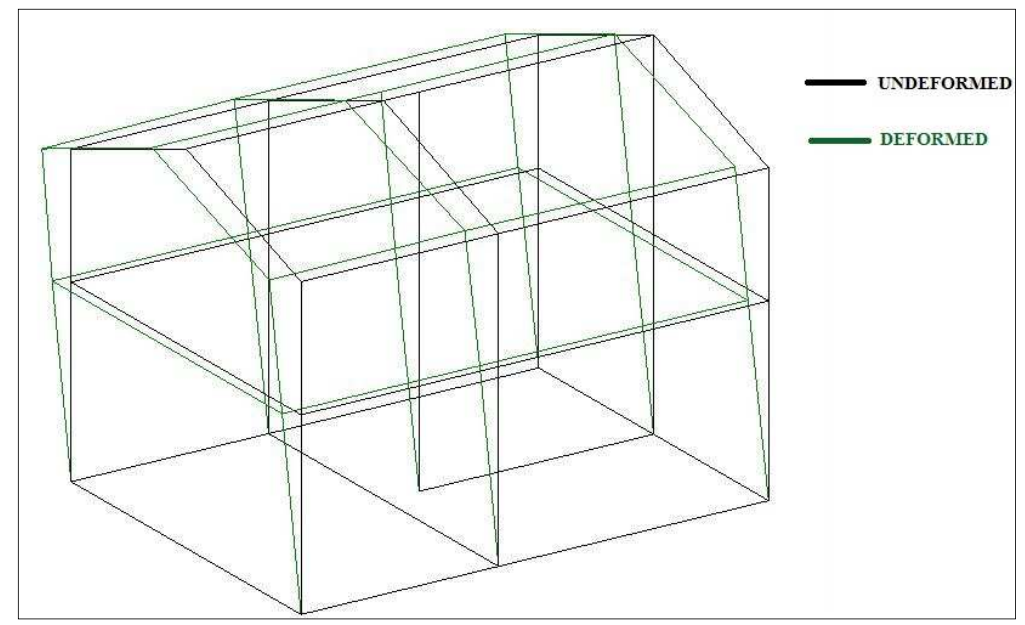

Figure 7 Fundamental mode shape obtained using ARTeMIS

Inter-storey drift. After processing the data obtained from the LVDTs and the optical acquisition system, the maximum inter-storey drifts were computed based on the displacements recorded by the latter and expressed in the table below.

Table 1: Maximum inter-storey drift values measured at first floor

\begin{tabular}{|c|c|c|c|}
\hline PGA & $0.07 \mathrm{~g}$ & $0.28 \mathrm{~g}$ & $0.5 \mathrm{~g}$ \\
\hline Inter-storey drift at first floor & 0.001 & 0.007 & 0.018 \\
\hline Inter-storey drift at roof level & 0.001 & 0.003 & 0.01 \\
\hline
\end{tabular}

Shear, slippage and wall uplift. In the first stage of the test $(0.07 \mathrm{~g})$, the shear deformation, slippage and wall uplift values were negligible. During the tests with $0.28 \mathrm{~g}$ PGA, the maximum shear deformation measured was $70 \mathrm{~mm}$ in the wall GLW01_Y and increased to $140 \mathrm{~mm}$ in the tests of $0.5 \mathrm{~g}$ PGA. The highest value of wall slippage during the tests of $0.28 \mathrm{~g}$ and $0.5 \mathrm{~g}$ was recorded by the LVDT that was placed at the base of the western wall (GLW02_Y), closer to the north-west corner, where a pronounced sliding between the logs in the upper portion was seen. The values of wall uplift were very low even for the tests of $0.28 \mathrm{~g}$. The highest value of wall uplift was $9 \mathrm{~mm}$ and recorded by the LVDT at the internal wall GLW04_X during the 0.5g test. (Refer Figure 4 for the wall orientations in the building plan)

Hold down forces. The maximum tensile forces recorded by the load cells during the $0.5 \mathrm{~g}$ test are seen in Figure 8. The magnitude of the forces is low with the peak tensile force measured being $0.82 \mathrm{kN}$. The peak tensile hold down forces measured during the tests with PGAs of $0.07 \mathrm{~g}$ and $0.28 \mathrm{~g}$ are negligible. This is because the load cells were attached to the vertical through bolts provided between the sill logs and the foundation that were very rigid and did not give scope for any sort of rocking motion. 


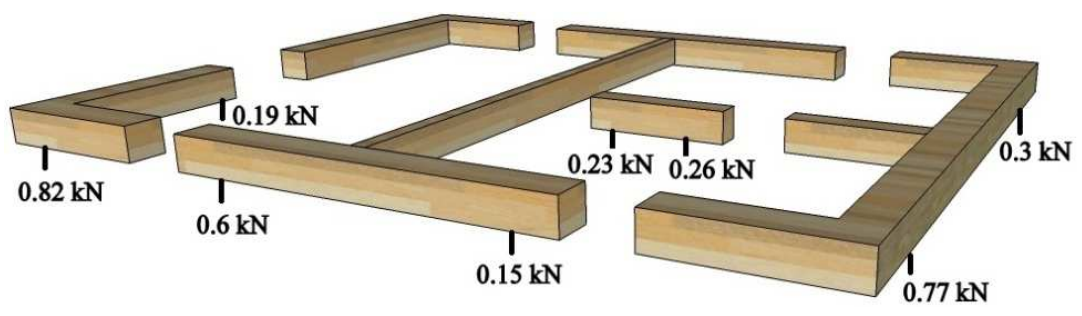

Figure 8 Maximum tensile hold down forces measured during the $0.5 \mathrm{~g}$ test

\section{Conclusions}

The work presented in this paper focuses on the seismic performance of log-houses and suggests that the house possesses good seismic resistance. Dynamic characterization tests revealed that the fundamental frequency of the structure was initially $5.389 \mathrm{~Hz}$ and then decreased to $5.109 \mathrm{~Hz}$ while the numerical model developed during the pre-design of the test indicated a fundamental frequency of $4.97 \mathrm{~Hz}$. The magnitude of the frequency decrease suggests that even if there were hidden damages, they were minor. The magnitude of the hold down forces that were measured during the test was low and the displacements of the walls were also within limits. The carpentry joints remained intact and the log profiles enabled a perfect fit between successive logs, which is a significant improvement from traditional log houses. The fast pace and ease of construction and the absence of major damage in the building indicate that this form of log construction would be a viable option in areas that have high seismic risk, provided the climatic conditions are suitable.

\section{Acknowledgement}

The authors acknowledge all participants in the SERIES Project "Multi-storey timber buildings" in particular, Alfredo Campos Costa and Paulo Candeias from LNEC, for the interesting discussion and help on the data acquisition and analysis.

\section{References}

[1] Hirai Takuro, Takeo Kimura, Kuniyoshi Yanaga, Yoshihisa Sasaki, Akio Koizumi, Lateral resistance of log constructions, Proceedings of the 8th world conference on timber engineering, WCTE. Lahti, Finland 163 (2004) 251-254.

[2] Branco J.M., Araujo J.P., Structural behaviour of log timber walls under lateral in-plane loads, Engineering Structures. 40 (2012), 371-382. URI: http://hdl.handle.net/1822/19907.

[3] European committee for standardization, Structural timber - Strength classes EN 338:2003 CEN, Brussels, Belgium 2003.

[4] SAP 2000, CSI Analysis Reference Manual for SAP2000. Version v14. Computers \& Structures Inc., Berkeley, USA.

[5] ARTeMIS Extractor, Structural Vibration Solutions, Denmark. 